\title{
Aging, Health, and the "Electronic Church"
}

\author{
JUDITH C. HAYS, PhD \\ LAWRENCE R. LANDERMAN, PhD \\ DAN G. BLAZER, MD, PhD \\ HAROLD G. KOENIG, MD, MHSc
}

Duke University Medical Center

JACKSON W. CARROLL, PhD

Duke University

MARC A. MUSICK, PhD

University of Michigan

\begin{abstract}
We tested whether elders substitute religious media use for church attendance when health declines (using multidimensional disengagement theory) with data from a multiracial, population-based sample in the Bible Belt $(N=2,971)$. In adjusted models, 3-year declines in functional status were significantly associated with concurrent reduction in frequency of church attendance but not with any change in rates of religious media (TV/radio) use. Age-related declines in church attendance were substantively explained by declining functional ability. Changes in religious media use were independent of age and less sensitive to declining functional status or service attendance than to cultural heritage such as race, socioeconomic status, and rural upbringing. Our data do not support the hypothesis that elders with deteriorating health substitute increased engagement with religious media as their participation in organizational religious activities is reduced. However, applicability of the substitution hypothesis to other dimensions of nonorganizational religiousness (e.g., prayer) awaits similar scrutiny.
\end{abstract}

In the past two decades, gerontologists have increased their scrutiny of the association between health and religion. Their findings suggest a generally positive relationship between religiousness and physical 
and mental health in late life (cf., Koenig \& Futterman, 1995, for a review). This association is most robust for organizationally oriented religiousness, such as attendance at religious services (Blazer \& Palmore, 1976; Gartner, Larson, \& Allen, 1991; Levin \& Vanderpool, 1987; Witter, Stock, Okun, \& Haring, 1985), and has not been explained by the superior functional health or social support of churchgoing elders (Idler \& Kasl, 1992; Levin, Chatters, \& Taylor, 1995).

Nonorganizational religious activities (NORA) appear to have a more complex relationship to health in late life. Listening to religious programs on television and radio, praying, and reading religious literature are reported to increase with age, unlike organizational religious activities (ORA), which remain stable or decline as persons age (Blazer \& Palmore, 1976; Markides, Levin, \& Ray, 1987). The putative cause of this age-related increase in NORA is that elders substitute NORA for ORA as they become more physically impaired. A relationship between "physical infirmities" and listening to church services on the radio was noted as early as 1949 (Cavan, Burgess, Havighurst, \& Goldhamer). More recently, NORA have shown positive cross-sectional associations with functional impairment and poor physical health (Ainlay, Singleton, \& Swigert, 1992; Koenig, Moberg, \& Kvale, 1988; Levin et al., 1995; Mindel \& Vaughan, 1978) and less consistent associations with aspects of mental health, including depression, anxiety, and morale (Koenig, Kvale, \& Ferrel, 1988; Koenig et al., 1997; Krause, 1992). This study examines the interrelationships among health status, organizational religiousness, and one dimension of nonorganizational religiousness, i.e., use of electronic religious media.

AUTHORS' NOTE: The research for this publication was performed pursuant to Contract N01-AG-1-2102 with the National Institute on Aging, in support of the Established Populations for Epidemiologic Studies of the Elderly (Duke) and to the Mental Health Clinical Research Center Grant No. 2 P30 MH40159. The content of this publication does not necessarily reflect the views or policies of the U.S. Department of Health and Human Services. Address correspondence to Judith C. Hays, RN, PhD, Box 3875, Duke University Medical Center, Durham, NC 27710. 


\section{THEORETICAL CONSIDERATIONS}

Mindel and Vaughan (1978) proposed that a theory of multidimensional disengagement would explain the age-related decline in organizational religious participation coupled with an increase in private religious activities. Their refinement of Cummings and Henry's (1961) social disengagement theory, incorporating the critique of Hochschild (1975), posited a transformation in the way in which elders enact their roles as religious while responding to the challenge of deteriorating health. Mindel and Vaughan (1978) proposed that aged persons with declining health disengage from associational spheres of religious activity but not necessarily from other spheres, particularly those that are more personal and subjective; indeed, the latter often retain and may increase in salience.

Mindel and Vaughan (1978) provided empirical evidence for differential disengagement that was in the hypothesized direction: low levels of ORA were not matched by low levels of NORA among functionally impaired elders. However, their sample was small and nonrandom, and their estimates of effects were minimally adjusted for other factors related to religiousness and health. Later research, although lending support to multidimensional disengagement theory, remains inconclusive (see Levin, 1989, for a review). Needed are specific tests of the hypothesis that "declines in health. . .engender heightened private expressions of religiosity" (Levin, 1989, p. 141).

\section{METHODOLOGICAL CONSIDERATIONS}

To test the hypothesis that poor health increases NORA, four major methodological weaknesses in prior studies should be addressed. These include the use of aggregated measures of NORA, restriction of focus to a single dimension of health status, neglect of competing explanations for significant associations, and nearly exclusive dependence on cross-sectional models.

Aggregation of NORA. A potential weakness in the extant literature concerns the aggregation of NORA into single scales of unknown psychometric properties. In one sample of elders, reliability was 
considerably lower for a composite measure of NORA that combined frequencies of religious media use and Bible reading than for composite measures of either ORA or religious coping (Krause, 1995). Commonly grouped NORA may well lack face validity as uniformly nonorganizational, private, personal, or subjective. As Hoover (1988) has shown, televangelists often encourage involvement in a distinctly organizational dimension of religious media use by providing opportunities for formal affiliation of viewers with television programs such as the Christian Broadcasting Network's 700 Club. Use of religious media may occur in the company of others and thus not be entirely private (Wuthnow, 1987). Furthermore, even solo viewers or listeners of religious programs often perceive themselves as participants in a ritual service of worship with a community of like-minded believers (Alexander, 1994). Finally, the experience of attending a religious service may be just as personal or subjective as that of listening to religious broadcasts. Overall, the psychometric properties of summary NORA scales remain understudied.

Furthermore, the few studies that have examined health correlates of disaggregated NORA suggest that each constituent item in a composite scale may be associated differently with specific dimensions of health. In one sample of elders, depressive symptoms were significantly associated with frequent viewing of religious television but not with frequent prayer, whereas poor physical health was associated with high levels of both NORA measures (Koenig et al., 1997). Among African American elders, health disability was significantly associated with religious media use, but not with reading religious materials, prayer, or requests for prayer (Taylor \& Chatters, 1991). On the other hand, satisfaction with health was not related to any measure of NORA in an all-aged sample of African American adults (Levin \& Taylor, 1993). Finally, specific NORA may be associated differently with potential confounders of the relationship between health and religion. For example, Koenig, Ford, George, Blazer, \& Meador (1993) reported that anxiety disorder was associated with frequent media use in young adults and with frequent prayer in middle-aged adults, but with neither measure of NORA in elders.

The dearth of empirical studies of religious media and health belies the prevalence of religious media use among U.S. adults, especially 
elders. In 1987, 221 television stations and 1,370 radio stations were classified as exclusively religious in program content (Frankl, 1990). Estimates of the size of the audience tuning in regularly to what Stacey and Shupe (1982) have termed the "electronic church" vary from 7 million to 40 million, most frequently falling in the 10 million to 20 million range (Bruce, 1990; Gerbner et al., 1984; Hoover, 1988). Whatever its size, there is general agreement that elders are overrepresented in that audience, as they are in church congregations (Barna, 1991; Buddenbaum, 1981; Gerbner et al., 1984; Hoover, 1988). Use of religious media is strongly correlated with church affiliation (Wuthnow, 1987), and religious embeddedness is more characteristic of elderly persons than of any other age group (Barna, 1991). Content analyses show that many religious programs address "social topics" (e.g., death and dying) and other "problems" (e.g., poor health) especially relevant to elders (Abelman \& Neuendorf, 1985, 1987).

Dimensions of health. A second weakness in previous analyses is the failure to accommodate multiple dimensions of health as potential change agents (Mindel \& Vaughan, 1978). In some studies, health is not tested directly; instead, age is assumed to be a marker of physical decline (Gaddy \& Pritchard, 1985). When tested concurrently, age and functional impairment (as well as other dimensions of health) may demonstrate distinctly different magnitudes of effect on particular NORA.

Competing explanations. Crude estimates of health effects on specific NORA should be tested for the confounding effects of other risk factors. Confounding may occur where a third factor is associated with both religion and health. Social support deficits and demographic factors present two compelling examples of potential confounders. Religious media use has been associated positively with social integration and feelings of belonging, as well as negatively with feelings of loneliness (Horsfield, 1984). The medium, the message, and the personalities associated with religious programs can furnish a sense of companionship, communication substitution, and shared interactive experience (Abelman, 1987; Buddenbaum, 1981; Comstock, Chaffee, Katzman, McCombs, \& Roberts, 1978; Davis \& Edwards, 1975; 
Hoover, 1988; Rubin, 1982). Thus, deficits in social support, shown to increase morbidity and mortality (Berkman, 1995; George, 1996), may also increase the use of religious media in late life, especially among elders for whom bereavements, residential changes, and the out-migration of younger family members are common.

Religious media use also varies within demographic subgroups. Religious media use is higher for African Americans than for Whites and is particularly high among African American elders (Levin, Taylor, \& Chatters, 1994; Taylor, Chatters, Jayakody, \& Levin, 1996); the traditionally powerful role of religion in African American culture has been suggested as a potential causal factor (Chatters \& Taylor, 1989). Women are overrepresented (often as much as two to one) in audiences for religious media as are the disadvantaged: less educated, blue-collar, lower-income persons (Alexander, 1994; Barna, 1991; Buddenbaum 1981; Hoover, 1988; Stacey \& Shupe, 1982). Some investigators have attributed the robust negative relationship between social class and religious media use to a culture of poverty and the tendency of the powerless to identify vicariously with religious media personalities (Tamney \& Johnson, 1984). However, elevated religious media use may be spuriously associated with health declines where demographic subgroups in the sample are both more religious and also more disabled or ill.

Prospective design. Finally, there is a striking lack of longitudinal studies examining the putative impact of health on NORA. Without such prospective designs, causal direction cannot be directly tested. The explicit but untested assumption has been that poor health causes NORA to increase over time (Ainlay et al., 1992; Blazer \& Palmore, 1976; Koenig, Moberg, \& Kvale, 1988; Mindel \& Vaughan, 1978). This assumption underlies both theodicy models of health and religion, in which religiousness increases to ameliorate suffering such as physical illness (Idler, 1994), and suppressor models of health and religion, in which physical illness triggers religiousness for its suppressive effect on mood impairment (Koenig et al., 1997; Wheaton, 1985). Longitudinal tests of these models as they regard religious media use are not available. 


\section{HYPOTHESES}

In light of these considerations, we hypothesize, following Mindel and Vaughan (1978), that

1. declining health in elders leads to a reduction in organizational religious activity (ORA), here operationalized as frequency of attendance at religious services;

2. declining health also leads to an increase in nonorganizational religious activity (NORA), here operationalized as frequency of use of religious media (which are substituted for ORA); and

3. if substitution of NORA for ORA is taking place,

(a) increased use of religious media (NORA) should be positively correlated with a reduction in religious service attendance (ORA), and

(b) the (hypothesized) increase in religious media use associated with declining health should be smaller when the effects of change in ORA (reduction of service attendance) are controlled.

Methods

\section{DESIGN AND SAMPLE}

This study used a prospective cohort design. Data for the study came from the Duke University site of the Established Populations for Epidemiologic Studies of the Elderly (EPESE), a stratified random household sample of five contiguous counties (one primarily urban and four primarily rural) in the north-central Piedmont area of North Carolina (Cornoni-Huntley et al., 1990). Durham County (1990 population: 181,835 persons in 291 square miles) is home to a major research university, several colleges, and portions of a major scientific research park, Research Triangle Park. The four rural counties (combined 1990 population: 130,916 persons in 1,706 square miles) include numerous small towns and rural farm and nonfarm areas (U.S. Bureau of the Census, 1994). Prior to data collection, households were stratified by racial characteristics to generate a sample in which approximately $55 \%$ of the respondents would be African American and $45 \%$ would be non-African American, mostly White. Sample 
weights were developed to adjust for the probability of selection within households of varying sizes, to adjust for differential nonresponse, and to match the demographic characteristics of the fivecounty area, as estimated by the U.S. Bureau of the Census. These weights redistribute responses to the true racial distribution of the 1985 population: 36\% African American and 64\% non-African American.

Face-to-face baseline (Wave 1 ) interviews $(n=4,162)$ were conducted in the respondents' homes during 1986, and in-person follow-up interviews (Wave 2) took place 3 years later. Respondents present at both interviews $(n=2,971)$ were included in these analyses. Subjects lost to the follow-up were randomly distributed across religious media user groups at the baseline but reported more chronic illness severity and less mobility capacity than the effective sample in logistic regression analyses. The effective sample was primarily female, with an average age in the early seventies. Most respondents reported that they attended church at least once a week and watched/listened to religious TV or radio at least once a week, and most described themselves as "born again" or having had a lifechanging religious experience. Two thirds of female respondents and two fifths of male respondents reported daily prayer or Bible study. Religious preference was predominantly Christian Protestant, primarily Baptist (60\%) and Methodist (14\%). Descriptive characteristics of the sample are summarized in Table 1.

\section{ASSESSMENT}

Our dependent variables for Hypothesis 1 and Hypotheses 2 and 3 were Wave 2 measures of church attendance ("How often do you go to religious meetings or services?") and use of religious media ("How often do you listen to religious television or religious radio?"), respectively. Both variables were scaled on six levels: never, once or twice a year, every few months, once or twice a month, once a week, or twice a week or more (ranges $=0-5$ ). Wave 1 (baseline) scores for these two variables were included as independent (control) variables in all models, as indicated below. Item wording remained constant at the baseline and the follow-up interviews. 
Table 1

Descriptive Statistics for the Sample by Gender

\begin{tabular}{|c|c|c|c|c|c|c|c|c|}
\hline \multirow{3}{*}{$\begin{array}{l}\text { Characteristic } \\
\text { Baseline (Wave I) } \\
\text { Variables }\end{array}$} & \multicolumn{4}{|c|}{ Women $(\mathrm{n}=1981)$} & \multicolumn{4}{|c|}{$\operatorname{Men}(\mathrm{n}=990)$} \\
\hline & \multicolumn{4}{|c|}{ Weighted } & \multicolumn{4}{|c|}{ Weighted } \\
\hline & $\mathbf{n}$ & $\%$ & $\overline{\mathbf{X}}$ & SD & $\mathbf{n}$ & $\%$ & $\overline{\mathbf{X}}$ & SD \\
\hline Religious service attendance & & & 4.3 & 1.6 & & & 4.1 & 1.7 \\
\hline Never & 230 & 13.2 & & & 152 & 15.8 & & \\
\hline 1-2/year & 85 & 4.4 & & & 58 & 6.3 & & \\
\hline Every few months & 119 & 5.4 & & & 71 & 6.5 & & \\
\hline $1-2 /$ month & 359 & 15.2 & & & 161 & 14.0 & & \\
\hline 1/week & 750 & 38.8 & & & 337 & 36.5 & & \\
\hline $2+/$ week & 431 & 22.8 & & & 207 & 20.9 & & \\
\hline Frequency of religious media use & & & 4.6 & 1.6 & & & 4.2 & 1.8 \\
\hline Never & 174 & 12.1 & & & 147 & 18.1 & & \\
\hline $1-2 /$ year & 45 & 2.9 & & & 35 & 4.3 & & \\
\hline Every few months & 67 & 4.8 & & & 36 & 5.2 & & \\
\hline $1-2 /$ month & 141 & 7.9 & & & 96 & 9.4 & & \\
\hline 1/week & 781 & 38.4 & & & 403 & 38.8 & & \\
\hline $2+/$ week & 761 & 34.0 & & & 267 & 24.2 & & \\
\hline Frequency of prayer/study & & & 4.1 & 1.4 & & & 3.2 & 1.7 \\
\hline Rarely/never & 218 & 11.7 & & & 267 & 29.2 & & \\
\hline Few/month & 103 & 4.7 & & & 83 & 7.5 & & \\
\hline 1/week & 185 & 9.9 & & & 142 & 14.6 & & \\
\hline $2+/$ week & 166 & 7.6 & & & 94 & 9.4 & & \\
\hline Daily & 1,274 & 66.1 & & & 372 & 39.4 & & \\
\hline Born again/life changed (versus not) & 1,565 & 77.6 & & & 679 & 68.8 & & \\
\hline \multicolumn{9}{|l|}{ Functional ability } \\
\hline Basic ADLs & & & 0.1 & 0.5 & & & 0.1 & 0.5 \\
\hline Household ADLs & & & 0.2 & 0.4 & & & 0.1 & 0.3 \\
\hline Cognitive ADLs & & & 0.1 & 0.3 & & & 0.1 & 0.3 \\
\hline Mobility & & & 0.3 & 0.4 & & & 0.2 & 0.4 \\
\hline Age (years) & & & 72.7 & 6.0 & & & 71.7 & 5.5 \\
\hline African American race & 1,088 & 35.4 & & & 522 & 33.9 & & \\
\hline Married & 492 & 38.6 & & & 699 & 79.8 & & \\
\hline Annual income $(\times \$ 1,000)$ & & & 11.3 & 10.4 & & & 16.8 & 13.1 \\
\hline Education (years) & & & 9.6 & 3.7 & & & 9.2 & 4.5 \\
\hline Urban residence & 1,144 & 58.1 & & & 491 & 52.0 & & \\
\hline \multicolumn{9}{|l|}{ Childhood residence } \\
\hline Rural & 1,364 & 63.9 & & & 693 & 66.0 & & \\
\hline Small town & 337 & 19.1 & & & 157 & 17.0 & & \\
\hline Medium town & 203 & 11.6 & & & 95 & 11.8 & & \\
\hline Suburb & 22 & 1.6 & & & 10 & 1.2 & & \\
\hline Large city & 52 & 3.8 & & & 35 & 4.0 & & \\
\hline \multicolumn{9}{|l|}{ Self-rated health } \\
\hline Excellent & 276 & 15.2 & & & 150 & 16.9 & & \\
\hline Good & 796 & 42.5 & & & 401 & 40.4 & & \\
\hline Fair & 643 & 30.8 & & & 321 & 32.4 & & \\
\hline Poor & 250 & 11.5 & & & 114 & 10.3 & & \\
\hline
\end{tabular}


Table 1 Continued

\begin{tabular}{|c|c|c|c|c|c|c|}
\hline \multirow{3}{*}{$\begin{array}{l}\text { Characteristic } \\
\text { Baseline (Wave I) } \\
\text { Variables }\end{array}$} & \multicolumn{3}{|c|}{ Women $(\mathrm{n}=1981)$} & \multicolumn{3}{|c|}{$\operatorname{Men}(\mathrm{n}=990)$} \\
\hline & \multicolumn{3}{|c|}{ Weighted } & \multicolumn{3}{|c|}{ Weighted } \\
\hline & $\mathbf{n}$ & $\%$ & SD & $\mathbf{n}$ & $\%$ & SD \\
\hline Chronic illness score & & 0.9 & 0.8 & & 1.0 & 0.8 \\
\hline Cognitive impairment & & 0.1 & 0.3 & & 0.1 & 0.2 \\
\hline Depression score (summed) & & 2.9 & 3.1 & & 2.1 & 2.8 \\
\hline Social network size & & 13.7 & 6.8 & & 14.7 & 7.0 \\
\hline Amount of social interaction & & 14.7 & 6.4 & & 13.9 & 6.9 \\
\hline Amount of help received & & 8.8 & 2.6 & & 8.5 & 2.8 \\
\hline Amount of help given & & 7.7 & 2.7 & & 8.7 & 3.0 \\
\hline Availability of confidant & & 2.7 & 0.6 & & 2.6 & 0.7 \\
\hline Can count on family/friend & & 2.9 & 0.4 & & 2.8 & 0.4 \\
\hline Number of negative life events & & 0.7 & 0.9 & & 0.6 & 0.9 \\
\hline
\end{tabular}

ADLs: Activities of daily living.

The primary independent variables were measures of health status at the baseline and Wave 2 interviews. Health status was operationalized using measures of functional ability, because changes in this aspect of health were considered more likely to have an impact on attendance at religious services than change in any other health measures.

The EPESE questionnaires included a modified version of the Katz activities of daily living (ADLs) index (Branch, Katz, Kniepmann, \& Papsidero, 1984), with all items scored on a 3-point scale; dichotomous instrumental activities of daily living (IADL) items derived from the Older Americans Resources and Services (OARS) Multidimensional Functional Assessment Questionnaire (Fillenbaum, 1988); and dichotomous measures of mobility derived from the RosowBreslau Health Scale (Rosow \& Breslau, 1966). Selected Katz and OARS items were used to construct scales measuring each of the three dimensions of functional limitation proposed by Johnson and Wolinsky (1994): (a) basic ADLs (bathing, dressing, transferring from bed to chair, and using the toilet), (b) household ADLs (meal preparation, shopping, housework), and (c) cognitive ADLs (managing money, using the telephone, and eating). In addition, two Rosow-Breslau items (climbing stairs and walking one half mile) were used to construct a scale assessing mobility. Each of these four scales is scored by 
counting the number of tasks a respondent is unable to perform without help from another person or special equipment (Landerman \& Fillenbaum, 1997). Thus, for all scales, a zero score indicates freedom from impairment; maximum impairment is indicated by scale scores of 4 for basic ADLs, 3 for household ADLs or cognitive ADLs, and 2 for mobility.

A second independent variable measuring change in religious service attendance between the baseline and the follow-up was included in tests of Hypothesis 3 (elders in declining health substituted the use of religious media for religious service attendance). This change variable was constructed by subtracting the Wave 1 score for religious service attendance from the corresponding Wave 2 score. The Wave 1 score for religious service attendance was included as an independent (control) variable in any model where the change score form of that variable appeared as an independent variable.

Five categories of covariates were evaluated as possible confounders of the hypothesized relationships. All were measured at Wave 1. (a) Two other dimensions of religiousness were assessed: devotional religiousness, operationalized as the frequency of prayer, meditation, or Bible study; and experiential religiousness, assessed from responses to the item: "Are you a 'born again' Christian or have you had any religious experience that changed your life?" (b) Demographic variables included race, income, years of formal education, density of current geographic residence (urban vs. rural as defined by the U.S. Bureau of the Census), and density of childhood geographic residence. (c) Social environment variables included marital status and six measures of social support (Cornoni-Huntley et al., 1990): the number of persons in the respondent's immediate social network, the number of personal contacts a respondent had in the past month, satisfaction with the support of a confidant, satisfaction with the level of social interaction, and how much instrumental assistance was given to or received from family and friends. (d) Four measures of health (other than functional ability) were assessed as potential confounders. Each is a known correlate of functional health and, to the degree of correlation with religious media, each was tested for confounding effects on the relationship between these primary variables. Physical health was scaled as a summary measure combining information on the presence and severity of five chronic conditions: heart problems, hypertension, 
diabetes, stroke, and cancer (Galanos, Fillenbaum, Cohen, \& Burchett, 1994). Mental health was assessed with the Short Portable Mental Status Questionnaire measuring cognitive impairment (Pfeiffer, 1975) and the Center for Epidemiologic Studies-Depression Scale measuring mood impairment (Radloff, 1977). Self-rated health was ranked as excellent, good, fair, or poor (Cornoni-Huntley et al., 1990). (e) Negative life events were assessed with a scale summing the number of significant, negatively evaluated events (e.g., illnesses or deaths of family or friends, divorce, residential moves, worsening financial or legal problems, retirement) reported by each respondent as having occurred during the year prior to the baseline interview (Cornoni-Huntley et al., 1990).

\section{ANALYSIS}

All analyses were performed using SAS statistical software (SAS, 1990), version 6.12. Zero-order correlation analysis was used to examine relationships at the baseline among measures of religiousness and measures of functional status. A residualized change model (using linear regression procedures with options for standardized betas and tolerances) was constructed to test each hypothesis. Residualized change models take the form of $y_{2}=y_{1}+x_{1-k}+e$, where $y_{2}=$ the dependent variable measured at Wave 2, $y_{1}=$ the dependent variable measured at Wave $1, x_{1-k}=$ independent variables and covariates, and $\mathrm{e}=$ the error term. For each model, Wave 2 scores on the appropriate dependent variable were regressed on scores from the corresponding Wave 1 measure, independent variables, and covariates.

The interpretation of the (unstandardized) coefficients in a residualized change model is as follows. The coefficient for the Wave 2 functional impairment score represents the effect of change in function on 3-year change in religious service attendance (Hypothesis 1) and religious media use (Hypotheses $2 \& 3$ ). The effect of change is adjusted for the main effect of functional status at the baseline. Thus, if there is support for Hypothesis 1, one would observe significant and negative coefficients for Wave 2 measures of functional status, because more impairment and less frequent attendance were hypothesized. Conversely, if there is support for Hypothesis 2, significant and 
positive coefficients associated with Wave 2 functional status measures would suggest that elders were engaging in more use of religious media as functional impairment increased. If there is support for Hypothesis 3, the significance of these positive coefficients would be reduced when change in religious service attendance is controlled. Covariates (and Wave 1 control measures of change variable) with coefficients of a negative sign predict declines in the outcome variable over time, whereas those with a positive sign predict increases. The observed effect of the baseline dependent variable $\left(y_{1}\right)$ represents its effect on the dependent variable as measured at the follow-up $\left(\mathrm{y}_{2}\right)$ (Kessler \& Greenberg, 1981).

To avoid multicollinearity (and its attendant unstable parameter estimates and inflated standard errors), variance inflation factors and eigenvalues were assessed for evidence of collinearity. No problems were found. As a further check on overcontrolling for health status, parameter estimates are presented for disability measures when entered separately and simultaneously in adjusted models of change in religious activities.

All multivariable models were weighted such that results could be generalized to the total population from which the sample was drawn and also downweighted such that significance tests would not be biased by an inflated sample size. In addition, all multivariable models were subjected to adjustments of significance tests using SUDAAN 7.00 - a software package that adjusts standard errors of independent variables to reflect a complex survey design (Shah, Barnwell, \& Bieler, 1995).

All analyses were performed separately by gender. The rationale for gender stratification is that widespread gender differences have been found for all the primary variables examined in this article, including religious activity, physical and mental health, and social support (for a review, see Idler, 1994). Separate analyses for men and women would be expected to demonstrate the varying salience of health decline and other factors by sex and permit comparability to other extant literature (Idler \& Kasl, 1992; Koenig, Kvale, \& Ferrel, 1988; Levin \& Markides, 1986). Because differences in the final models for men and women were trivial, results for the combined sample, adjusted for gender, are presented. 
Results

Scores on the various dimensions of religiousness were highly correlated (Table 2). Respondents who reported one kind of religious behavior at the baseline were considerably more likely to experience other kinds and thus to hold generally the same relative rank in the total group with respect to church attendance, religious media use, and private religious activity. The lowest correlation was between church attendance and religious media use. Among both men and women, the baseline scores on all four dimensions of functional status showed highly significant positive correlations with each other, significant negative correlations with church attendance, and somewhat less significant positive correlations with use of religious TV and radio. Because higher functional status scores indicate impairment, these zero-order correlations suggest that impairment of functional status was associated at the baseline with less frequent church attendance and (to a lesser extent) more frequent religious media use. Baseline private religious activity was uncorrelated with functional status, with one exception: Men with impaired mobility reported less private religious activity.

Models of church attendance at Wave 2 provided consistent support for Hypothesis 1, which had predicted that declining health would lead to reduced frequency of organizational religious activity among elders. Coefficients for Wave 2 disability measures were consistently negative in the church attendance model (Table 3 ), suggesting that increasing functional impairment predicts declining rates of church attendance (and conversely, that functional improvements predict increased attendance). These associations were statistically significant when entered separately and lost some robustness when entered simultaneously. The associations were adjusted for the stable nature of church attendance over time (reflected in the positive coefficients for the baseline church attendance) and for the positive effect of other dimensions of religiousness on increasing church attendance. The associations were also controlled for the baseline levels of disability.

Overall, the variables included in this model predicted $54 \%$ of the variance in changes in church attendance in this population. Covariates of change in church attendance differed in only two respects 


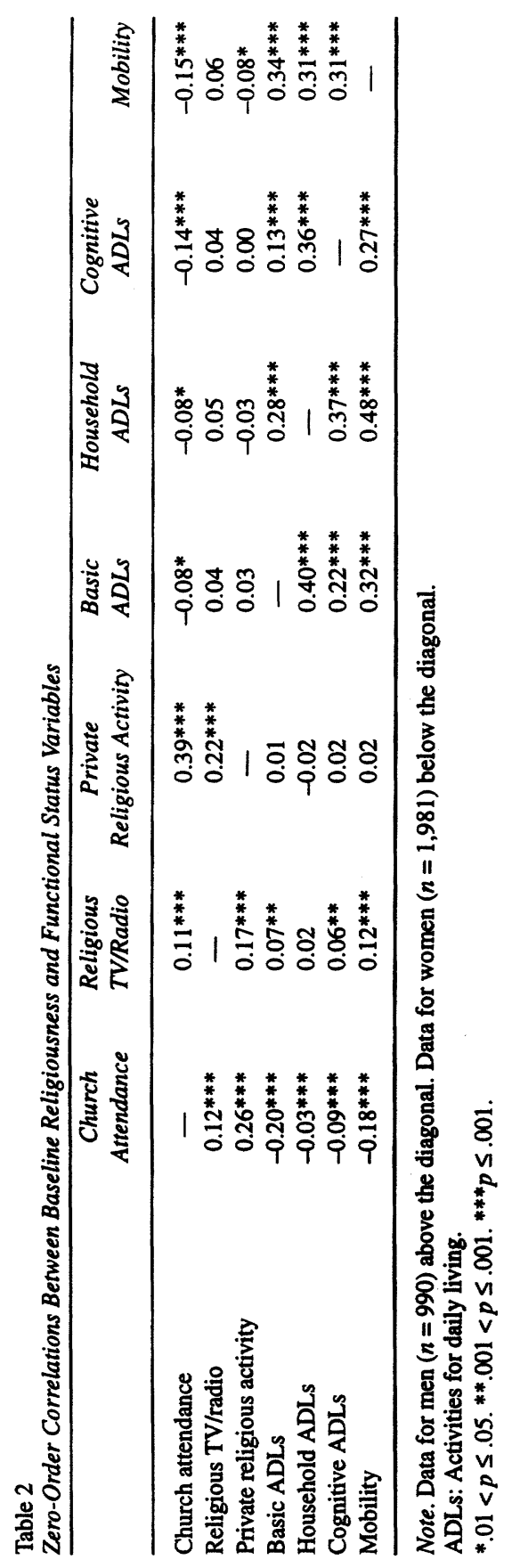


between men and women (untabled). Women with higher levels of social interaction at the baseline increased their church attendance over time more than women reporting lower baseline social interaction; men with high incomes increased their attendance more than lower-income men.

Models of religious media use at Wave 2 provided no support for Hypothesis 2, which had predicted that declining health would lead to increased frequency of NORA. No significant relationship was found between increased functional impairment and increased religious media use in the total sample (Table 3 ) or separately among men or women (untabled). Both men and women showed generally stable levels of religious media use, as indicated by a significant and positive coefficient for Wave 1 religious radio and television use. African American race, lower income, and rural childhood were the most powerful covariates of increased religious media use. This model explained $40 \%$ of the variation in changes in religious media use in this population.

There was also no evidence in support of Hypothesis 3, which predicted that elders with deteriorating health would increase their use of religious media as their frequency of church attendance declined. When a change score representing the trajectory of church attendance was added to the model testing Hypothesis 2, no significant relationship was found for either men or women (untabled). Declines in church attendance had no explanatory effect on the relationship between declining function and increasing use of religious media. Indeed, there was no relationship to explain: Change in church attendance was unrelated to change in religious media use. Where religious media use increased, the predictors of that increase were primarily previous religiousness and demographic factors. Where religious media use increased relative to poor function at the baseline, subjects did not change their level of church attendance concurrently (or else they had already decreased their attendance prior to Wave 1).

Substitution of religious media for church attendance could have occurred selectively among those whose health declined. However, in similar models of religious media use limited to subjects with declining health, the baseline functional impairment, severity of decline in functional impairment, and changes in church attendance all failed to predict increased religious media use (untabled). 


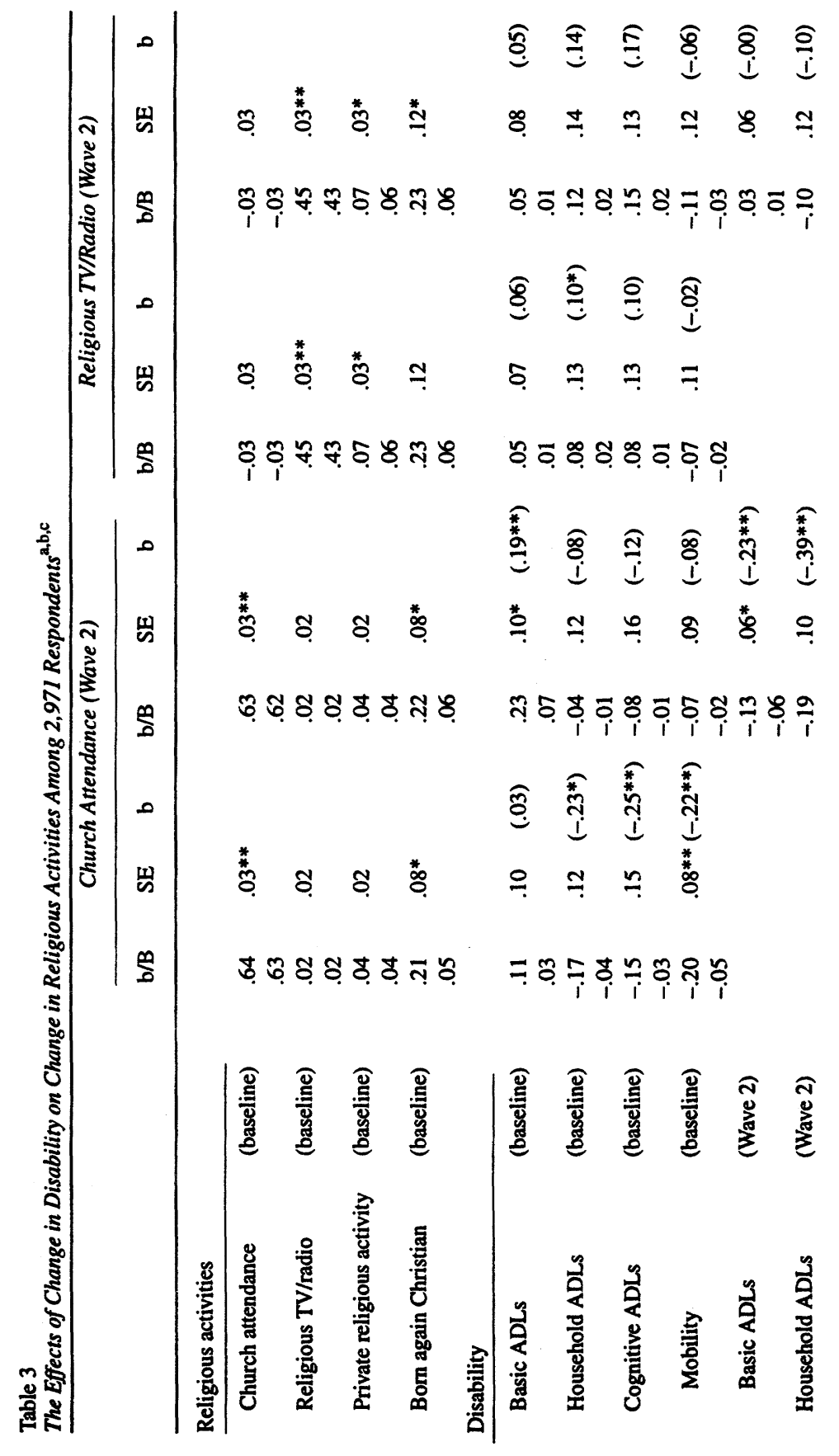


莤

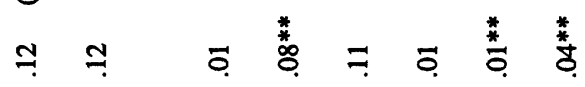

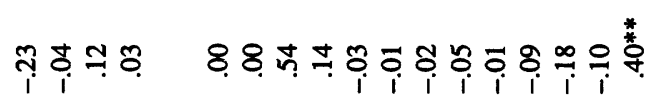

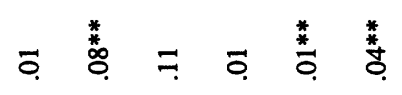

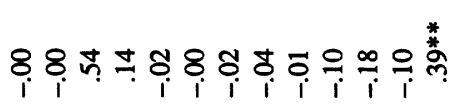

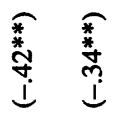

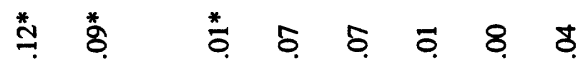

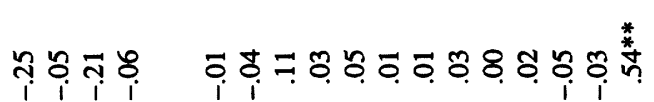

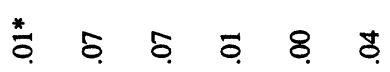

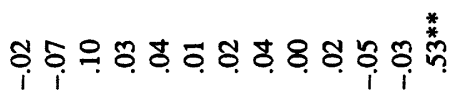

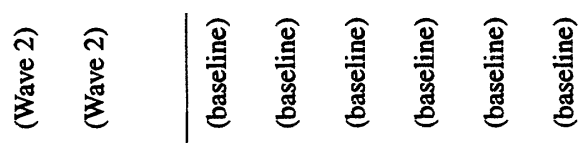

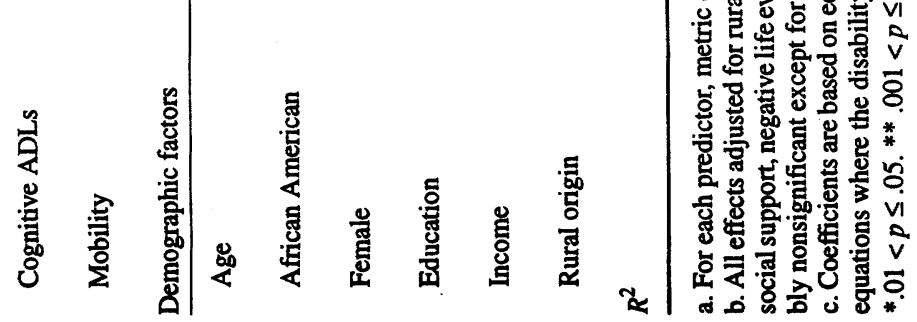




\section{Discussion}

Overall, religious media use in this population conformed only minimally to the pattern predicted by multidimensional disengagement theory. This conclusion is predicated on three primary findings. (a) Over a 3-year period, increased functional impairment significantly reduced attendance at religious services. (b) However, neither increased functional impairment nor less frequent attendance at religious services was relevant to changes in the use of religious media over the same period; thus, there is little support for the contention that elders experiencing declining health substitute engagement with religious broadcasts for participation in church services. (c) Religious media use was less sensitive to declines in health and service attendance than to cultural heritage.

Health, age, and organizational religiousness. Declining health in late life (operationalized here as increasing functional impairment) favors disengagement from associational religious spheres. This makes intuitive sense; church attendance is more difficult for elders who have problems with climbing stairs, walking distances, or accomplishing the basic activities of daily living without assistance than it is for their unimpaired counterparts. This finding is consistent with a growing body of extant literature documenting a positive relationship between health and organizational religiousness (reviewed in Koenig \& Futterman, 1995).

We also found that chronological age was no longer a risk factor for declining attendance at religious services when changes in functional status were controlled. Crude age-related declines in church attendance have been reported among Mexican American and Anglo elders in the southwestern United States (Markides et al., 1987); our study extends this finding by suggesting that age-related declines in attendance among community-dwelling African American and White elders in the southeastern United States are substantively explained by declines in functional ability. In summary, the norm in this population of elders was stable engagement with the organizational church, although severity of baseline functional limitations and deteriorating functional ability posed some risk for disengagement over time. 
Health, age, and engagement with the electronic church. Men and women responded similarly to health impairments with respect to religious media use. Across the sample, respondents' engagement with the electronic church showed little change as their mobility or other functional abilities declined. Furthermore, within this sample of elders, changes in the use of religious media were uniformly independent of age. There was no evidence of differences among age groups with respect to increased or decreased engagement with this particular dimension of religiousness. This finding is consistent with reports by Markides et al. (1987) that age has little direct effect on other dimensions of NORA (e.g., prayer) or on self-rated religiosity.

Substitution of the electronic for the organizational church. Increasing engagement with the electronic church did not occur at the expense of church service attendance in late life. Nor was substitution in evidence selectively among disabled elders. Attendance at the electronic and organizational churches appears to be entirely independent phenomena, although some of their predictors overlap.

These findings have several implications. Although impairment of functional status generally predicted reduced frequency of attendance at worship services among elders, the magnitude and significance of effects varied considerably among the different dimensions of functional status assessed in this study. (Cognitive decline was the most powerful predictor of reduced church attendance among men, followed by reduced ability to perform household ADLs; declining basic ADLs performance and mobility showed smaller effects. Among women, declining mobility and deterioration of ability to perform basic ADLs predicted reduction in frequency of church attendance.) In contrast, the effects of declining functional status on the frequency of religious TV or radio use were negligible; the four dimensions of functional status lacked predictive power whether they were entered individually or simultaneously into models of Wave 2 religious media use. Furthermore, increased frequency in use of religious media had no association whatever with reduction in attendance at religious services.

Cultural heritage was far more uniformly determinative of increased religious media use than was functional health. Early antecedent forces that significantly predicted "tuning in" to the electronic 
church among both men and women included race, socioeconomic status, and rural upbringing. We found that African American subjects reported both greater levels of the baseline use of religious media and increased engagement with religious media above the baseline level during the subsequent 3-year period-even with class, geography, social support, and health status held constant. These results are consistent with reports by Taylor et al. (1996) and Levin et al. (1994) that African Americans use religious media more frequently than Whites.

Indeed, analyses of multiple national probability samples by Taylor et al. (1996) demonstrate consistently higher levels of participation in NORA on every measure available (as well as consistently higher rates of church attendance) among African Americans as compared to Whites. Whether or not the African American elders in this study were more religious than their White counterparts, they may have tuned into religious broadcasts with greater frequency because they were more dissatisfied with secular radio and television. Abelman (1987) has found that adult viewers are often prompted to use religious media by dissatisfaction with secular television rather than by motives associated with religious ritual or information seeking. Alternatively, religious programs produced for African American audiences may have been of greater variety or of higher quality, or more accurately targeted to their intended audience, than those produced for White audiences.

We know little about which programs were accessed by elders in 1986 because local television ratings were not stratified by age (Nielsen Station Index, 1986), and radio ratings were collected primarily for persons younger than 65 (Raleigh-Durham Fall 1986 Arbitron Radio Market Report). Nonetheless, in future investigations where racial differences in the association of religion and health are hypothesized, the impact of religious media should be assessed, as there are clear racial differences in the propensity of elders to use religious media. The same caveat applies, perhaps more strongly, to class differences in the association of religiousness and health, in light of the excess risk among economically disadvantaged elders of multiple physical, functional, and mood impairments (Arber \& Ginn, 1993; George, 1996; Kaplan, Strawbridge, Camacho, \& Cohen, 1993). Krause (1995) surmised that early environmental deficits, such as low education, may also favor the use of religion as a coping device 
because other coping options associated with greater social status are not available.

Measures of social support such as network size, amount of interaction, the giving and receiving of instrumental help, the availability of a confidant, and satisfaction with social interaction were not significant as predictors of change in religious media use. We might have expected isolated elders to increase engagement with religious television or radio, but this did not occur. Indeed, marginally greater increases in frequency of religious media use were seen in married than in unmarried women. Other investigators have been surprised by similar findings (Young \& Dowling, 1987).

In conclusion, we found that the level of engagement of elders with religious media was largely independent of health. Elders were not inclined to substitute the electronic church for attendance at church services. Stability was characteristic of both organizational and nonorganizational religious activity among these elders. It is important for these findings to be confirmed in elderly populations where religiousness is not so prevalent and religious preference not so uniform as in the southeastern United States. Furthermore, although these data do not support the hypothesis that elders in declining health substitute increased religious media use as the frequency of church attendance decreases, the applicability of the substitution hypothesis to other NORA (e.g., prayer) awaits similar scrutiny.

\section{REFERENCES}

Abelman, R. (1987). Religious television uses and gratifications. Journal of Broadcasting and Electronic Media, 31, 93-107.

Abelman, R., \& Neuendorf, K. (1985). How religious is religious television programming? Journal of Communication, 35(1), 98-110.

Abelman, R., \& Neuendorf, K. (1987). Themes and topics in religious television programming. Review of religious research, 29(2), 152-174.

Ainlay, S. C., Singleton, R., Jr., \& Swigert, V. L. (1992). Aging and religious participation:

Reconsidering the effects of health. Journal for the Scientific Study of Religion, 31, 175-188.

Alexander, B. C. (1994). Televangelism reconsidered: Ritual in the search for human community (American Academy of Religion Studies in Religion No. 68). Atlanta, GA: Scholars Press.

Arber, S., \& Ginn, J. (1993). Gender and inequalities in health in later life. Social Science and Medicine, 36, 33-46.

Barna, G. (1991). What Americans believe: An annual survey of values and religious views in the United States. Ventura, CA: Regal Books. 
Berkman, L. F. (1995). The role of social relations in health promotion. Psychosomatic Medicine, 57, 245-254.

Blazer, D., \& Palmore, E. B. (1976). Religion and aging in a longitudinal panel. The Gerontologist, 16, 82-85.

Branch, L. G., Katz, S., Kniepmann, K., \& Papsidero, J. A. (1984). A prospective study of functional status among community elders. American Journal of Public Health, 74, 266-268.

Bruce, S. (1990). Pray TV: Televangelism in America. New York: Routledge.

Buddenbaum, J. M. (1981). Characteristics and media-related needs of the audience for religious TV. Journalism Quarterly, 58, 266-272.

Cavan, R. S., Burgess, E. W., Havighurst, R. J., \& Goldhamer, H. (1949). Personal adjustment in old age. Chicago: Science Research Associates.

Chatters, L. M., \& Taylor, R. J. (1989). Age differences in religious participation among Black adults. Journal of Gerontology: Social Sciences, 44, S183-S189.

Comstock, G., Chaffee, S., Katzman, N., McCombs, M., \& Roberts, D. (1978). Television and human behavior. New York: Columbia University Press.

Cornoni-Huntley, J., Blazer, D. G., Lafferty, M. E., Everett, D. F., Brock, D. B., \& Farmer, M. E. (1990). Established populations for epidemiologic studies of the elderly (Vol. 2): Resource data book (NIA Publication No. 90-495). Washington, DC: National Institute on Aging.

Cummings, E., \& Henry, W. (1961). Growing old: The process of disengagement. New York: Basic Books.

Davis, R. H., \& Edwards, A. E. (1975). Television: A therapeutic tool for the aged. Los Angeles: Ethel Percy Andrus Gerontology Center, University of Southern California.

Fillenbaum, G. G. (1988). Multidimensional functional assessment of older adults. Hillsdale, NJ: Lawrence Erlbaum.

Frankl, R. (1990). A hybrid institution. In R. Abelman \& H. S. Hoover (Eds.), Religious television: Controversies and conclusions (pp. 57-61). Norwood, NJ: Ablex.

Gaddy, G. D., \& Pritchard, D. (1985). When watching religious TV is like attending church. Journal of Communication, 35, 123-131.

Galanos, A. N., Fillenbaum, G. G., Cohen, H. J., \& Burchett, B.M. (1994). The comprehensive assessment of community dwelling elderly: Why functional status is not enough. Aging Clinical \& Experimental Research, 6, 343-352.

Gartner, J., Larson, D. B., \& Allen, G. D. (1991). Religious commitment and mental health: Review of the empirical literature. Psychology and Theology, 19, 6-25.

George, L. K. (1996). Social and economic factors related to psychiatric disorders in late life. In E. W. Busse \& D. G. Blazer (Eds.), Textbook of geriatric psychiatry (2nd ed., pp. 129-153). Washington, DC: American Psychiatric Press.

Gerbner, G., Gross, L., Hoover, S., Morgan, M., Signorielli, N., \& Cotugno, H. E. (1984). Religion and television: A research report by the Annenberg School of Communications, University of Pennsylvania and the Gallup Organization, Inc. (2 vols.). Philadelphia: Committee on Electronic Church Research, University of Pennsylvania Press.

Hochschild, A. (1975). Disengagement theory: A critique and proposal. American Sociological Review, 40, 553-569.

Hoover, S. M. (1988). Mass media religion: The social sources of the electronic church. Newbury Park, CA: Sage.

Horsfield, P. G. (1984). Religious television: The American experience. New York: Longman.

Idler, E. L. (1994). Cohesiveness and coherence: Religion and the health of the elderly. New York: Garland.

Idler, E. L., \& Kasl, S. V. (1992). Religion, disability, depression, and the timing of death. American Journal of Sociology, 97, 1052-1079. 
Johnson, R. J., \& Wolinsky, F. D. (1994). Gender, race, and health: The structure of health status among older adults. The Gerontologist, 34, 24-35.

Kaplan, G. A., Strawbridge, W. J., Camacho, T., \& Cohen, R. D. (1993). Factors associated with change in physical functioning in the elderly: A six-year prospective study. Journal of Aging and Health, 5, 140-153.

Kessler, R. C., \& Greenberg, D.F.(1981). Linear panel analysis: Models of quantitative change. New York: Academic Press.

Koenig, H. G., \& Futterman, A. (1995). Religion and health outcomes: A review and synthesis of the literature. Position paper presented at the National Institute on Aging/Fetzer Institute-sponsored Methodological Approaches to the Study of Religion, Aging and Health, March 16-17, Bethesda, MD.

Koenig, H. G., Ford, S. M., George, L. K., Blazer, D. G., \& Meador, K. G. (1993). Religion and anxiety disorder: An examination and comparison of associations in young, middle-aged, and elderly adults. Journal of Anxiety Disorders, 7, 321-342.

Koenig, H. G., Hays, J. C., George, L. K., Blazer, D. G., Larson, D. B., \& Landerman, L. R. (1997). Modeling the cross-sectional relationships between religion, physical health, social support and depressive symptoms. American Journal of Geriatric Psychiatry, 5, 131-144.

Koenig, H. G., Kvale, J. N., \& Ferrel, C. (1988). Religion and well-being in later life. The Gerontologist, 28, 18-28.

Koenig, H. G., Moberg, D. O., \& Kvale, J. N. (1988). Religious activities and attitudes of older adults in a geriatric assessment clinic. Journal of the American Geriatrics Society, 36, 362-374.

Krause, N. (1992). Stress, religiosity, and psychological well-being among older Blacks. Journal of Aging and Health, 4, 412-439.

Krause, N. (1995). Religiosity and self-esteem among older adults. Journal of Gerontology: Psychological Sciences, 50B, P236-P246.

Landerman, R. L., \& Fillenbaum, G. G. (1997). Differential relationships of risk factors to alternative measures of disability. Journal of Aging and Health, 9, 266-279.

Levin, J. S. (1989). Religious factors in aging, adjustment, and health: A theoretical overview. In W. M. Clements (Ed.), Religion, aging and health: A global perspective (pp. 133-146). New York: Haworth.

Levin, J. S., Chatters, L. M., \& Taylor, R. J. (1995). Religious effects on health status and life satisfaction among Black Americans. Journal of Gerontology: Social Sciences, 50B, S154-S163.

Levin, J. S., \& Markides, K. S. (1986). Religious attendance and subjective health. Journal for the Scientific Study of Religion, 25, 31-40.

Levin, J. S., \& Taylor, R. J. (1993). Gender and age differences in religiosity among Black Americans. The Gerontologist, 33, 16-23.

Levin, J. S., Taylor, R. J., \& Chatters, L. M. (1994). Race and gender differences in religiosity among older adults: Findings from four national surveys. Journal of Gerontology: Social Sciences, 49, S137-S145.

Levin, J.S., \& Vanderpool, H. Y. (1987). Is frequent religious attendance really conducive to better health?: Toward an epidemiology of religion. Social Science and Medicine, 24, 589-600.

Markides, K.S., Levin, J. S., \& Ray, L. A. (1987). Religion, aging, and life satisfaction: An eight-year, three-wave longitudinal study. The Gerontologist, 27, 660-665.

Mindel, C. H., \& Vaughan, C. E. (1978). A multidimensional approach to religiosity and disengagement. Journal of Gerontology, 33, 103-108.

Nielsen Station Index. (1986). Chicago: A. C. Nielsen. 
Pfeiffer, E. (1975). A Short Portable Mental Status Questionnaire for the assessment of organic brain deficit in elderly patients. Journal of the American Geriatrics Society, 23, 433-441.

Raleigh-Durham Fall 1986 Arbitron Radio Market Report, Adults 35-64 Average Quarter Hour Share, Monday-Sunday 6AM-Midnight Metro Estimates.

Radloff, L. S. (1977). The CES-D Scale: A self-report depression scale for research in the general population. Applied Psychological Measurement, 1, 385-401.

Rosow, I., \& Breslau, N. (1966). A Guttman Health Scale for the aged. Journal of Gerontology, 21, 556-559.

Rubin, A. M. (1982). Directions in television and aging research. Journal of Broadcasting, 26, 537-551.

SAS Institute, Inc. (1990). SAS/STAT User's Guide, Release 6 (4th ed.). Cary, NC: Author.

Shah, B. V., Barnwell, B. G., \& Bieler, G. S. (1995). SUDAAN Software for the Statistical Analysis of Correlated Data: User's Manual. Research Triangle Park, NC: Research Triangle Institute.

Stacey, W., \& Shupe, A. (1982). Correlates of support for the electronic church. Journal for the Scientific Study of Religion, 21, 291-303.

Tamney, J. B., \& Johnson, S. D. (1984). Religious television in Middletown. Review of Religious Research, 25, 303-313.

Taylor, R. J., \& Chatters, L. M. (1991). Nonorganizational religious participation among elderly Black adults. Journal of Gerontology: Social Sciences, 46, S103-S111.

Taylor, R. J., Chatters, L. M., Jayakody, R., \& Levin, J. S. (1996). Black and White differences in religious participation: A multisample comparison. Journal for the Scientific Study of Religion, 35, 403-410.

U.S. Bureau of the Census. (1994). County and City Data Book. Washington, DC: Superintendent of Documents.

Wheaton, B. (1985). Models of the stress-buffering functions of coping resources. Journal of Health and Social Behavior, 26, 352-364.

Witter, R. A., Stock, W. A., Okun, M. A., \& Haring, M. J. (1985). Religion and subjective wellbeing in adulthood: A quantitative synthesis. Review of Religious Research, 26, 332-341.

Wuthnow, R. (1987). The social significance of religious television. Review of Religious Research, 29, 125-134.

Young, G., \& Dowling, W. (1987). Dimensions of religiosity in old age: Accounting for variation in types of participation. Journal of Gerontology, 42, 376-380. 